\title{
Analyze the Impact of MPA System on Current Commercial Banks
}

\author{
Chaoqi Wang \\ School of Economies, Jinan University, Guangzhou, China \\ Email: abcwcq@qq.com
}

How to cite this paper: Wang, C.Q. (2017) Analyze the Impact of MPA System on Current Commercial Banks. Modern Economy, 8, 494-506.

https://doi.org/10.4236/me.2017.84037

Received: January 13, 2017

Accepted: April 4, 2017

Published: April 7, 2017

Copyright (C) 2017 by author and Scientific Research Publishing Inc. This work is licensed under the Creative Commons Attribution International License (CC BY 4.0).

http://creativecommons.org/licenses/by/4.0/

\section{cc) (i) Open Access}

\begin{abstract}
Since 2016, the People's Bank of China (PBOC) had adjusted the dynamic adjustment of discretionary reserve and the loan management mechanism which were implemented since 2011, to macro prudential assessment (MPA), in order to manage the diverse and complex asset of the financial sector fully and effectively, and strengthen the counter-cyclical adjustment of monetary policy, further improve the macro-prudential policy framework to guard against systemic risks and ensure the stability of the financial system. This paper will introduce the macro-prudential assessment system of the central bank, and then combine the system indicators to understand the impact of the system on the commercial banking business, in the research process mainly used literature analysis, historical research, comparative research, inductive analysis and other research methods, through the study we found that the implementation of macro-prudential assessment system conforms to the development trend of China's financial industry, and will help to grasp the real risks of banks and promote the stability of the financial system.
\end{abstract}

\section{Keywords}

Macro Prudential Assessment, Regulatory, Impact

\section{Introduction}

In December 29, 2015, the people's Bank of China held a meeting to deploy the improvement of consensual loan management, and decided to start the implementation of macro prudential assessment from 2016. The existing differential reserve dynamic adjustment and consensual loan management mechanism will upgrade to "macro prudential assessment system" (Macro Prudential Assessment, hereinafter referred to as MPA). The consensual loan management has been applied by the end of 2015, and the business model of the bank changed dramatically in the past few years, especially the shadow banking is quite popu- 
lar. In order to reduce the size of the credit, the banks had created a variety of channels, through these channels the real credit assets became interbank business, asset management business or investment banking business, etc. It can also be seen that the simple consensus loan management has become obsolete, and unable to restrain the release of bank funds, but also cannot grasp the substantive risks of banks. Upgrade to MPA management system is also in line with the development trend of China's financial industry. And it will have a great impact on the banking business once again.

This text will explain the rules of the MPA, and according this we can understand the banking business how to adjust. This text is divided into three parts: the first part gives an overall understanding of MPA system, describes the system of evaluation object, object classification, the unit in charge of assessment period, evaluation index, evaluation results. Incentives and exemptions; the second part is a detailed analysis of the MPA index system, the calculation process for about 14 of the seven indexes were analyzed, and combined with the current data of listed banks announced statements (including the ICBC, $A B C$, The Bank of China, CCB, Bank of Communications, CITIC, Shanghai Pudong, Minsheng Bank, China Merchants Bank, Everbright Bank, when it comes to the listed banks report, it included only 11 of the banks above, no longer note), see what indicators will become the targets of the bank; the third part is the impact on the banking business based on the first two parts to analyze the influence of MPA system on the banking business.

\section{The Overall Recognize of the MPA System}

\subsection{The Background of the MPA}

"Macro-prudence" was first appeared in June 1979, on the seminar about the conversion of international bank loan period, which was held by the Cook Commission (the predecessor of the Basel Committee on Banking Supervision). Until 1986, the Bank of International Settlements (BIS) released the latest innovation in the international banking research report, macro Prudential was first written into the official document. Later, with the outbreak of the Asian financial crisis, the concept of "macro-prudence" and related research has gradually been concerned.

After the financial crisis in 2008, the international regulatory authorities generally recognized that some of the fatal risks in the economic system under the micro-prudential supervision has been ignored, and the macro-prudential regulation can effectively compensate for the regulatory blind spot, therefore, demands for macro-prudential supervision macro-prudential supervision were sound in the world [1].

Since then, major economies and international organizations have begun to focus on strengthening the macro prudential supervision as the main content of the financial regulatory reform, the establishment of macro prudential regulatory framework has become the consensus of the international community. In 2009, the United States and the European Union announced the establishment 
of a macro-prudential regulatory system and a correspondent specialized agencies.

In April 2009, the G20 Summit announced the establishment of the Financial Stability Board (FSB), an international macro-prudential regulatory organization for global financial stability that will assess the vulnerabilities of different financial systems and promote coordination and information exchange among different regulatory bodies and provide supervisory guidance and support to large-scale cross-border financial institutions with systemic importance (including the four major Chinese banks), to support emergency response plans for cross-border crisis management, and to jointly develop the early warning system for the financial system with the International Monetary Fund.

On June 29, 2009, the Bank for International Settlements (BIS) issued an annual report calling on all countries and the international community to adopt macro-prudential principles to mitigate the negative impact of the kin-cyclicality of the economic system.

China's central bank also announced in 2010 to start macro prudential supervision, and in 2011 began to establish a differential reserve dynamic adjustment and loan management mechanism to prevent systemic financial risks. Until December 29, 2016, the central bank has taken further action to improve the macro Prudential policy framework.

\subsection{The Overall Recognize of the MPA}

The evaluation object of MPA Including commercial banks, rural banks, foreign banks, financial companies, financial leasing companies, auto finance companies, trust and investment companies. Of course, mainly for banks.

The classification of MPA appraise objects are as follows. National Institute for systemically important institutions (N-SIFIs), Regional System Importance Organizations (R-SIFIs), and Common Institutions (CFIs) [1]. There are some differences in the criteria for achieving these objectives, and stricter for the systemically important institutions.

The unit which is in charge of MPA assessment. The MPA is administered and interpreted by the People's Bank and its Macro-Prudential Assessment Committee. N-SIFIs were evaluated by the National Macro-Prudential Assessment Board, and R-SIFIs and CFIs were evaluated by the provincial macro-prudential assessment committees.

MPA evaluation cycle. The evaluation frequency is once per quarter, it usually completed within one month after the quarter-end. People's Bank of China will test those indicators every month, once find abnormal warning, the bank will be given a window guidance if necessary.

MPA evaluation indicators. Those indicators include capital and leverage, balance sheets, liquidity, pricing, asset quality, cross-border financing risk, credit policy implementation. And all those seven spends include 14 indicators. People's Bank of China will adjust the index, weighting, associated parameters and the methods of evaluation according to the needs of macro-control. 
MPA evaluation result. The result can be divided into $\mathrm{ABC}$, if it is $\mathrm{A}$, it means the seven indicators are all excellent (great line is 90); and then implement optimal incentive. Except $\mathrm{A}$ and $\mathrm{C}$, it is $\mathrm{B}$, then implement normal stimulation. if capital, leverage or pricing any of this are not in compliance, or balance sheet, liquidity, asset quality, cross-border financing risk, credit policy implementation any two of those indicators are not catch the standard (standard line 60), the agencies will get $\mathrm{C}$, then implement worst stimulation.

MPA evaluation of incentive and restraint mechanisms. For different rating, implement differentiated reserve rates about their deposit reserve. The A institutions implement the incentive interest rate, whose statutory reserves rates will float up 10\% - 30\% (current 10\%).the C institutions implement binding interest rates, whose statutory reserves rates will float down 10\% - 30\% (current 10\%); B institutions continue to maintain statutory reserve rates.

Evaluation of MPA exemption. Consider the lack of historical data required for the establishment of new institutions, and the initial development is often rapid. In principle, those institutions will not be incorporated into the MPA within three years after its establishment. Referring to its macro-prudential assessment system to strengthen self-discipline, and accompanied with the necessary guidance [2].

\section{The Detailed Analyses of Each Index of MPA System}

\subsection{Capital and Leverage}

This is an indicator of a veto with only one vote, if the agencies cannot catch 60 points, its rating is $\mathrm{C}$. This indicator can be subdivide into three indicators (of which the "total loss absorption capacity" temporarily not score, so there are actually only two effective indicators): one is the capital adequacy ratio (80 points), the other is the leverage ratio (20 points). Analysis is as follows:

1) The capital adequacy ratio

If the macro-prudential capital adequacy ratio is $\mathrm{C}^{\star}$ (or more), it is 80 points, between $\left[\mathrm{C}^{\star}-\mathrm{T}, \mathrm{C}^{\star}\right]$ is 48 to 80 minutes, under the $\mathrm{C}^{\star}-\mathrm{T}$ is 0 . Here $\mathrm{T}$ is tolerance, tentatively scheduled for $4 \%$.

Capital adequacy ratio $=$ capital held by institutions/Risk - weighted assets.

Macro prudential capital adequacy ratio $\left(\mathrm{C}^{\star}\right)=\alpha \times$ (minimum capital adequacy ratio of $8 \%+$ reserve capital + system importance additional capital + counter-cyclical buffer capital).

In this formula $\alpha$ is the structural parameter, and its reference value is 1 .

The central bank will make some adjustment combined with the soundness of financial institutions and the implementation of credit policies.

There are many variables in the formula of $\mathrm{C}^{\star}$, but generally it can be understood as follows: choose the largest local banks as a benchmark, whose $\mathrm{C}^{\star}$ is about $10.6 \%$, and $C^{*}$ should add $0.4 \%$ during the Fourth quarter, that is $11 \%$. And other smaller financial institutions can reduce $0 \%$ to $0.5 \%$ based on the benchmark according to its size, while the financial companies need to add $2 \%$. Meanwhile, General credit growth below (GDP + CPI), $C^{\star}$ can also decrease by 
about $0.3 \%$. Finally, the central bank will make some adjustment according to the stability of financial institutions and the implementation of credit policies.

From the recent annual report of the Banks, we can find that for most banks they will be able to reach 80 points, even if some small banks are not up to, due to the tolerance of $\mathrm{T}$ is $4 \%$, that is $11 \%-4 \%=7 \%$, we will get at least 48 points. Therefore, we believe that this indicator is not too strong limit on banks. From the Bank's annual report which were published in 2015, the lowest is Ping An Bank, which is $10.94 \%$, but also above the basic standard. The other 10 banks are all above $11 \%$.

2) Leverage ratio

If the index is above $4 \%$ (included), then the institutions will get 20 points, otherwise it will get 0 , there is no interpolation between the transition. This indictor is quite rigid, if the institutions cannot get 20 points it be rated as level A.

Leverage ratio $=$ tier-one capital held by the organization/adjusted balance of assets inside and outside the table.

From the annual report of the banks in 2015, Ping An Bank minimum, 4.94\%, also reached. The remaining 10 banks are more than $5 \%$.

\subsection{Pricing Behavior}

This is also an indicator which one vote can decide the result, if the sore is under 60 , then the ratio is level $\mathrm{C}$. This indicator directly refers to the market rate pricing self-regulation mechanism to score the relevant assessment results of interest rate pricing. It is mainly to investigate whether the bank has high interest and other behaviors.

The above two indicators are one-vote veto, as long as there is a non-compliance it will be rated as $\mathrm{C}$. The following five indicators, if there is only one non-compliance, it can also be rated as B.

\subsection{Assets and Liabilities}

The balance of assets can be divided into three indicators: generalized credit (accounted for 60 cents), commissioned loans (accounted for 15 cents), interbank liabilities (accounted for 25 cents). Analyze as follows:

1) Generalized credit

For the nationally important institutions, if the credit growth rate of generalized and the target M2 growth deviation are not more than 20 percentages then it can get 60 points, otherwise its 0 points. As the regional importance of institutions, if it's not more than 22 percentages; and for the general institutions, it should not more than 25 percentages. There is no interpolation in the middle of the transition, therefore, the index is relatively rigid.

Generalized credit refers to the total balance of loans, bond investment, equity and other investments, repurchase agreements and non-depository financial institutions deposited in the credit balance sheet. M2 growth tentatively set at 13\%, so the generalized credit growth should be controlled below 15.6\% (N-SIFIs), $15.86 \%$ (R-SIFIs), $16.25 \%$ (CFIs). This growth rate is same as the bank credit 
growth in previous years, but after expanded the statistical standard, the bank's asset growth space is quite limited. Due to the rigidity of the index, and the weight of the index is 60 points, once the standard of this index is not satisfied, then it will lead to the major indicators of assets and liabilities is substandard, so the banks will certainly try to meet this indicator.

According to the bank's annual report in 2015, five banks five banks failed to meet the standards, Bank of Communications (17.03\%), CITIC Bank (28.28\%), Shanghai Pudong Development Bank (22.33\%), China Merchants Bank (20.36\%), China Everbright Bank (18.82\%), while ICBC, CCB, Bank of China is relatively low. Therefore, the index may have two effects, one is there will be some constraints on the banks of the business expansion, and second, in the MPA assessment point, the institutions whose general credit growth are faster may put assets under the name of a lower growth rate of institutions.

2) Entrusted loan

And it is same as the generalized credit. If there is no such business, then it can get full marks, that is 15 points.

3) Interbank liabilities

For the national importance institutions, if the interbank debt accounts for less than 25 percent of total liabilities. it can get 25 points, and if the total liabilities of the interbank liabilities are not more than $33 \%$, it can get 15 to 25 , but if the interbank liabilities accounted for more than $33 \%$ percent of the total liabilities, it is 0 points, and there was a difference between the regional importance bodies and the national importance institutions, that is, if the institutions want get 25 points, the total liabilities of the interbank liabilities should not more than $28 \%$ per cent; and for the general body, the total liabilities of the interbank liabilities should not exceeding $30 \%$. And, the others are same.

This index seriously affects the interbank business, but because of the weight of the index is small, only 25 points, and has a certain flexibility, so the institutions can control the proportion of indebtedness within 33\%, then it can get 15 points. At the same time, if the first two index are full marks, then the major categories of indicators are 90 points and the institutions can meet the requirements of level A. From the 2015 annual reports of banks, 11 banks all meet the standard, among which 3 banks are close to the standard: CITIC Bank (24.76\%), Shanghai Pudong Development Bank (24.59\%) and Minsheng Bank (24.70\%).

\subsection{Liquidity}

This item can be subdivided into three indicators: liquidity coverage ratio (40 percent), net stabilization ratio (40 percent) and compliance with the reserve System (20 cents). Analyze as follows:

1) Liquidity coverage ratio (LCR)

If the current regulatory can conform to the standard of the indicators, the institutions can get 40 points, or else, it is 0 , there is no interpolation between the transition, so the index is relatively rigid. The current requirement is $70 \%$ in the first three quarters of 2016 and $80 \%$ in the fourth quarter. In addition, rural 
banks, branches of foreign banks and commercial banks whose assets less than 200 billion yuan may not apply to the liquidity coverage regulatory requirements, and those institutions calculated by 40 points.

According to the "commercial bank liquidity risk management measures (Trial)", commercial bank liquidity coverage ratio should be reached $100 \%$ before the end of 2018; in the transition period, should be reached $60 \%, 70 \%, 80 \%, 90 \%$, at the end of 2014, the end of 2015, the end of 2016 and the end of 2017. Therefore, the first three quarters of 2017 should be $80 \%$, in the fourth quarter, it should be $90 \%$.and the first quarter of 2018 should be $90 \%$, the first quarter of fourth should be $100 \%$.

Liquidity coverage ratio $=$ HQLA Reserve/Net outflows for the next 30 days.

HQLA Reserve is high-quality liquid assets reserves, Mainly includes first-tier assets and secondary assets, such as cash, excess reserves, or high grade bonds.

As the deposits within a month are all included in the cash outflows, this will have a bearing on the maturity mismatch of long-term assets with short-term funds. From the 2015 bank statements, 11 banks reached all standards, including 4 banks close to the standard line: China CITIC Bank (87.78\%), Shanghai Pudong Development Bank (78.31\%), Minsheng Bank (88.21\%), China Everbright Bank (84.78\%). Shanghai Pudong Development will not be up to the requirements of the Index in the fourth quarter of this year, and at the end of the year it will be $80 \%$.

2) Net stable capital ratio (NSFR)

It can get 40 points if the Net stable capital ratio is more than $100 \%$ (included). otherwise it is 0 . there is no interpolation between the transition, so the index is also relatively rigid.

Net stable capital ratio $=$ Stable funds available/Stable funds required for the business.

Net stable capital ratio can be regarded as an upgraded version of deposit and loan targets. The index of Deposits and loans only consider static balance, while the net stable capital ratio will take into account the source of the debt and the deadline and other factors together, it will be more refined. It can reduce the term of the asset-liability mismatch.

Compared with the traditional deposit-loan ratio indicators, this index has a subdivision on the stability of deposits. unlike large and medium enterprises, retail and small business have a more stable deposits, so the conversion ratio is higher, and this will encourage more banks take deposits from the retail and small business as more stable sources of debt.

3) Compliance with the reserve requirement system

If the institutions comply with the reserve requirement, they can get 20, or else it is 0 . there is no interpolation for transition, so the index is also relatively rigid.

This indicator will basically meet the standard. According to the above analysis, because of this 20 points are almost all available, then there are two good choices for the bank: first, assure the first two indicators to achieve the standard, 
so that the large category of indicators to get full marks; the other is to abandon one of the first two indicators, and the institutions still can get 60 points, and can't go so far as to be rated as level C.

Especially for some banks, when the other 6 major categories of indicators cannot reach 90 points, those institutions certainly cannot be rated as level A. Then you can choose to give up one of the highly mobile indicators, thus to maintain the flexibility of the business.

After the text edit has been completed, the paper is ready for the template. Duplicate the template file by using the Save As command, and use the naming convention prescribed by your journal for the name of your paper. In this newly created file, highlight all of the contents and import your prepared text file. You are now ready to style your paper [3].

\subsection{Asset Quality}

This indicator can be subdivided into two indicators: the rate of non-performing loans (accounted for 50 points), and the provision of coverage (accounted for 50 points). Analyze as following.

1) Non-performing loan ratio

If the institution's non-performing loan ratio is not higher than the same type of institutions which is in the same region, then they can get 50 points.

If the institution's non-performing loan ratio is higher but not $5 \%$ higher than the same type of institutions in the same region, then they can get $30-50$ points.

If the institution's non-performing loan ratio is $5 \%$ higher than the same type of institutions in the same region, then they can only get 0 points.

NPL ratio $=$ NPL balance/loan balance.

The standard of the non-performing loan rate of the same type of organization refers to the quarterly data published by the banking supervision and administration institution.

This indicator cannot be adjusted by the banks in short time. it fluctuate with the macroeconomic cycle and fluctuations more. But according to the current banks' data, this indicator can get a higher score basically. Consider the 2015 annual report of Banks, there were 11 banks compliance. And Agricultural Bank (2.39\%) was the highest.

2) Provisioning coverage ratio

It is 50 points, if the Provisioning coverage ratio belong [150\%, $\infty$ ); and it is 30 - 50, if the Provisioning coverage ratio belong [100\%, 150\%); and 0 , if [0\%, $100 \%)$.

Provisioning coverage ratio $=$ loan impairment preparation balance/bad loan balance.

The Regulator's requirements for the provisioning coverage ratio is above $150 \%$, but recently, as the credit risk increased, a number of banks are close to the red line. According to the media's reports, the CBRC is considering a dynamic adjustment which is according with the minimum requirements of the regulatory. So, some banks may be downgraded to $130 \%$ or $140 \%$. Consider the 
2015 annual reports, there were 11 banks meet the standards, China Construction Bank (150.99\%) is the lowest.

\subsection{Cross-Border Financing Risks}

This indicator can be subdivided into three indicators: the range which exceed the upper limit of cross-border financing risk-weighted balance (60 points), the currency structure of cross-border financing (20 points), the term structure of cross-border financing (worth 20 points). Analysis is as follows:

1) The range which exceed the upper limit of cross-border financing riskweighted balance

If the range which exceed the upper limit of cross-border financing riskweighted balance is 0 , they can get 60 points. Otherwise, as every $1 \%$ increased of the range, its score should be deducted 2 points, stop till to 0 .

Cross-border financing risk Weighted balance cap $=$ capital or net assets $\times$ cross-border financing leverage ratio $\times$ macro-prudential adjustment parameters.

Among them, the macro-prudent regulatory parameters of financial institutions tentatively set at 1 .

Net assets, the financial institutions should use the core capital to calculate.

Cross-border financing leverage ratio, as for the financial institutions should be 0.8 . In other words, the cap of cross-border financing of financial institutions is $80 \%$ of the core capital

This index is primarily relating to banks who have cross-border business and is hardly a limiting factor currently.

2) The Currency Structure of Cross-border Financing

If the foreign currency debt is not less than $50 \%$, then they can get 20 points, If the foreign currency debt is less than $50 \%$, for each one percentage reduction, the deduction of score is 0.4 points.

Foreign currency denominated in RMB, which encourage the financial institutions to absorb offshore renminbi as a source of external debt to reduce exchange rate risk.

3) Term Structure of Cross-border Financing

If the proportion of medium and long-term foreign debts is not less than $50 \%$, they can get 20 points; If the proportion of medium and long-term foreign debts is less than $50 \%$, for each one percentage reduction, the deduction of score is 0.4 points.

The long-term external debt which is over 1 year is to encourage financial institutions to absorb long-term foreign debt in order to reduce the risk of mismatch period.

\subsection{Credit Policy Implementation}

This index can be subdivided into two indicators: implementation of the credit (70 per cent), the use of Central Bank funds (30 per cent). Analysis is as follows:

1) Credit performance

The score of this index is between 0 and 70 points, and is decided according 
with the results of credit policy-oriented evaluation.

The evaluation of credit policy oriented effect is evaluated by quantitative and qualitative together.

The evaluation of this index is according to the current macroeconomic situation and monetary policy-oriented development of assessment programs, and it covers a wide range, including promoting domestic demand, adjust the structure, energy saving, eliminate backward production capacity and other dimensions. And all of those are dominated by the people's Bank's evaluation.

This index is mainly in order to guide the bank's credit policy implementation, and also should be complied with the central bank's current monetary policy.

2) The use of central bank's funds

This index is assessing the use of central bank's funds (including agro-small loans, rediscount, etc.) which have credit-policy-oriented nature. During the evaluation period, if the institution does not use the central bank's funds, and they can get 20 points.

If the institution uses the central bank's funds, according to their repayment, interest rate and investment orientation, and whether or not pay back the principal and interest of central bank's funds on time and in full, the institution can get full score 20 points; or compliance 20 points, or non-compliance 0 points.

If the use of central bank funds to carry out business in line with the central bank's interest rate, the institution can get full score 5 points; or compliance 5 points, or non-compliance 0 points.

If the institution's investment direction is in line with central bank's capital investment requirements and not less than the total business volume of central bank requirements, the institution can get full score 5 points; or if it is compliance, then they can get 5 points; or if it is non-compliance, then they can get 0 points.

This indicator mainly encourages Bank funds in line with the Central Bank's current monetary policy.

\section{Impact on the Banking Business}

According to the above analysis, we believe that the biggest impact on the banking business are as follows. And we will analyze both positive and negative aspects.

\subsection{Positive Aspects}

\subsubsection{Low-Risk Assets Will Be Favored by the Bank}

As the capital and leverage indicators have a veto, and the sub indicators of capital adequacy ratio accounted for 80 points, so banks will treat the capital adequacy ratio as the number one indicator. This indicator's molecule is the capital held by institutions, and which is difficult to adjust in the short term. The denominator is the risk weighted assets, which can be adjusted in the short term. Then, the banks will reduce the risk weighted assets by the re allocation of assets. 
Therefore, low-risk assets will be more favored by banks, such as high-grade bonds, bank acceptance bills and so on.

\subsubsection{For Large and Medium-Sized Banks, Interbank Business Is Still the Focus}

Although the expansion of interbank business has been limited by its scale as mentioned above, it is still very loose, especially for large and medium-sized banks, whose have strong growth for their large base [4]. Generalized credit growth rate can be controlled within $15.6 \%$, the proportion of inter-industry debt can be controlled within 33\%, and thus they can still be assessed as level A. This ratio is still relatively loose.

\subsubsection{Promote the Internationalization of the RMB}

In the index of cross-border financing risks, guiding banks to allocate more RMB liabilities overseas will be a good channel for offshore RMB to backflow, and which can further promote the internationalization of RMB.

\subsubsection{Enhance the Central Bank's Voice in the Credit Policy}

In the model of one bank and three commissions, the central bank have more macro-level management, as for the implementation of credit policy, it is mainly relying on the three commissions supervision to the financial institutions' implementation.

However, in the MPA system, the implementation of this policy will make the central bank has a greater voice. This is also consistent with the trend that one bank and three commissions will be merged in the future [5].

\subsection{Negative Aspects}

\subsubsection{The Behavior of High Interest Storage Will Be Curbed}

At present, the marketization of interest rate has been basically achieved in form, the loan and deposit interest rate of one year or more can be priced independently by the bank. But in order to prevent vicious competition among banks, the central bank has given a very important component to the pricing behavior of banks, and this will make the behavior of high interest storage further be curbed.

\subsubsection{Lending Shift Will Become the Past, Active Management Is Becoming More Important}

Since the upgrading from the consensual credit management to the generalized credit management, and the expansion of the caliber, the shift of credit which was very popular in the past few years will no longer be valuable. The banks will pay more attention to the risks and benefits of the asset itself, rather than get the regulatory arbitrage though channel [6]. Then the ability to manage the assets will be the core competitiveness of the future banks.

4.2.3. For Small and Medium Banks, the Opportunity to Rely on the Rapid Expansion of Interbank Business will Become Smaller and Smaller Because of the limit of the banks' balance sheet, the past few years, it's harder for 
them, especially small and medium banks, due to their fewer affiliated agency, to expand by relying on the absorbing deposits.

Instead, relying on interbank debt and interbank investment to carry out the high-speed expansion of the scale is the best choice. Industrial Bank, Minsheng Bank and Ping An Bank are the representative banks whose business model has been recognized and imitated by the market. However, in the future, when in the MPA system, it will be difficult to reproduce this model which is rapid development and driven by the interbank business [7]. Because this rapid development will be limited by the growth rate of broad credit size, as well as the proportion of interbank liabilities to total liabilities.

\subsubsection{For Large and Medium-Sized Banks, Interbank Business Is Still the Focus}

Although the expansion of interbank business has been limited by its scale as mentioned above, it is still very loose, especially for large and medium-sized banks, whose have strong growth for their large base. Generalized credit growth rate can be controlled within $15.6 \%$, the proportion of inter-industry debt can be controlled within $33 \%$, and thus they can still be assessed as level A. This ratio is still relatively loose.

\subsubsection{Business Models That Mismatched Short-Term Liabilities and Long-Term Assets Will Be Affected}

Subject to the constraints of liquidity, this will have a certain impact on the banks' mismatch business.

Over the past few years, the return on assets decline rapidly, while the cost of bank's declined slowly, this made the mismatch business during the bank were very popular, and led to the money shortage event in June 2013. The term arbitrage business which use the short term debt and long-term assets has become a profit growth point of many banks. However, in the MPA system, the management of convective mobility indicators will have a certain influence to kind of business.

\section{Conclusions and Analysis}

In summary, the macro-prudential assessment system will help to improve the structure of regulatory constraints, help to enhance the autonomy of banks, and help to improve macro-risk controllability. To a certain extent, MPA will make commercial banks to pay more attention to the real risk of asset allocation, to adequate capital, to strengthening non-traditional credit control, and to day-today credit management.

Finally, this study, in practice, on the one hand will help commercial banks to actively respond to macro-prudential assessment system, and on the other hand it will help the bank management to make the right decisions, and develop a corresponding performance appraisal system. In academic, on the one hand, it enriches the theoretical research on the impact of central bank policy supervision on commercial banks, and on the other hand, it lays the theoretical foundation for the subsequent empirical research. 
Of course, because of my limited knowledge and ability, there are still some shortcomings in the analysis about the impact of MPA system on current commercial banks. Firstly, the banking system risk early warning, assessment and disposal failed to consider the impact of some of the more complex external market factors. In addition, we must take into account the reality of various financial institutions to develop a targeted regulatory program, and in the future, these issues remained need further analysis, and constantly improve the research results.

\section{References}

[1] Yin, Z.T. (2016) The Origin of the Macro-Prudential Assessment System. Financial View, 2, 36.

[2] Kang, H.F. (2016) The Recognize of China's Macro-Prudential Assessment System. Financial Accounting, 4, 65-71.

[3] Zheng, L.S. and Yang, X.C. (2016) The Countermeasures of Commercial Banks to Deal with Macro-Prudential Assessment System. The Chinese Banker, 6, 57-59.

[4] Chen, S.M. and Xu, J. (2016) Impact of MPA on the Incentine Mechanism of Small Financial Institutions. Chinese Banker, 12, 135-136.

[5] Zeng, G. (2016) Macro-Prudential Assessment System for Small and Medium-Sized Banks. Modern Bankers, 5, 60-61.

[6] Shang, X. and Zheng, G.Q. (2016) Enlightenment of Macro Prudential Assessment and Supervisory Rating on Improving Deposit Insurance Risk Rating. Financial Development Review, 4, 136-141.

[7] Zhang, Q. (2016) Macro-Prudential Assessment Mechanism and Coping Strategies of Commercial Banks. Hainan Finance, 10, 32-36.

\section{Submit or recommend next manuscript to SCIRP and we will provide best service for you:}

Accepting pre-submission inquiries through Email, Facebook, LinkedIn, Twitter, etc. A wide selection of journals (inclusive of 9 subjects, more than 200 journals)

Providing 24-hour high-quality service

User-friendly online submission system

Fair and swift peer-review system

Efficient typesetting and proofreading procedure

Display of the result of downloads and visits, as well as the number of cited articles

Maximum dissemination of your research work

Submit your manuscript at: http://papersubmission.scirp.org/

Or contact me@scirp.org 